\title{
RADIOTHERAPY AFTER NEOADJUVANT SYSTEMIC TREATMENT OF BREAST CANCER
}

\author{
KATARINA ANTUNAC \\ Division of Radiotherapy and Medical Oncology, University Hospital for Tumors, \\ Sestre milosrdnice University Hospital Center, Zagreb, Croatia
}

\begin{abstract}
Summary
When deciding on adjuvant radiotherapy in breast cancer patients, the decision is made based on the type of surgery (radical or conserving) and pathological report. In case systemic treatment is given before surgery, initial pathological report, which presents the backbone in decision making, is partly missing. Data from prospective randomized trials are lacking, and published retrospective data are inconsistent. Current guidelines are not clear for a large subset of patients. Also, guidelines and real-life data are often in discordance. This article aims to present literature data regarding the risk of locoregional relapse after neoadjuvant systemic treatment, the impact of radiotherapy on the risk of locoregional relapse, current clinical trial that is expected to give an answer in which subset of patients should adjuvant radiotherapy be performed and published clinical practice data.
\end{abstract}

KEYWORDS: breast cancer radiotherapy, breast cancer neoadjuvant systemic treatment

\section{Sažetak}

\section{RADIOTERAPIJA NAKON NEOADJUVANTNOG SUSTAVNOG LIJEČENJA RAKA DOJKE}

Kod postavljanja indikacije za adjuvantno zračenje bolesnica s rakom dojke vodimo se vrstom kirurškog zahvata (radikalni ili poštedni) te patohistološkim nalazom. U slučaju da je sistemska terapija provedena prije kirurškog zahvata, nedostaje dio patohistološkog nalaza koji je okosnica u donošenju odluke. Objavljenih prospektivnih randomiziranih studija nema a retrospektivni podaci su nekonzistentni. Trenutne smjernice nisu jasne za veliku podskupinu bolesnica. Osim toga smjernice i podaci iz kliničke prakse se često ne podudaraju. Cilj ovog rada je prikazati podatke iz literature po pitanju rizika nastanka lokoregionalnog relapsa nakon neoadjuvantnog sistemskog liječenja, učinak radioterapije na smanjenje rizika lokoregionalnog relapsa, kliničku studiju koja bi trebala dati odgovor kod koje skupine bolesnica bi bilo uputno provesti zračenje te objavljene podatke iz kliničke prakse.

KLJUČNE RIJEČI: zračenje raka dojke, neoadjuvantno sustavno liječenje raka dojke

\section{INTRODUCTION}

Adjuvant radiotherapy of breast cancer is undoubtedly effective treatment; it reduces the rate of local relapse, distant metastases, and improves survival. However, these effects can be limited in a certain subgroup of patients $(1,2)$. Radiotherapy is also associated with specific side effects, the most dangerous being cardiac toxicity and development of secondary cancers, and the most common being cosmetic ones $(3,4)$. Indication for adjuvant radiotherapy is based on the risk of local re- 
currence based on the type of surgical treatment (radical or breast-conserving) and complete pathologic analysis of untreated tumor and nodal tissues. Considerable volumes of prospective and retrospective literature support the use of radiotherapy in subgroups of patients. In general, adjuvant radiotherapy is indicated in patients with positive axillary lymph nodes and in all patients after breast-conserving surgery, except in those older than 70 years with pT1N0 hormone positive tumours, and in patients with pT3-4 tumours after mastectomy.

Neoadjuvant systemic treatment (NAST) of breast cancer is not a new approach; it started in 1970-es in patients with the locally advanced irresectable disease. The therapy aimed to achieve resectability. All those patients had a high risk of local recurrence, and all of them met the criteria for adjuvant radiotherapy (5). In the last 20 years, NAST is used in patients with small, initially resectable tumors. Despite advances in diagnostics, one cannot be sure of the initial extent of the disease since the complete pathological analysis of untreated tumor is lacking. Therefore, it can be challenging to estimate the risk of local relapse and justify adjuvant radiotherapy. Data from prospective randomized trials are still pending.

\section{LITERATURE DATA}

\section{Impact of neoadjuvant chemotherapy on local control}

Results of two meta-analyses show that breast cancer patients who were given neoadjuvant chemotherapy have a higher risk of local relapse when compared to patients that received chemotherapy postoperatively.

Mauri et al. evaluated nine randomized trials that included 3946 patients with breast cancer, comparing neoadjuvant and adjuvant chemotherapy, additional surgery and/or radiation regardless. Primary outcomes were death, disease progression, distant disease recurrence, and locoregional disease recurrence. There was no statistically or clinically significant difference between the two therapy arms regarding death $(R R=$ $0.99)$, disease progression $(R R=0.99)$, or distant disease recurrence $(R R=0.94)$. Neoadjuvant approach to chemotherapy was statistically significantly associated with increased risk of locore- gional recurrence $(R R=1.22)$, compared with the same therapy given postoperatively. This was even more expressed in a group of patients who had a complete clinical response and, therefore, received just radiation therapy without surgery $(R R=1.53)$. Trials were performed between 1983 and 1999. It is worth mentioning that taxanes were not given in any of the trials (6).

EBCTCG's meta-analysiss published in 2018 analyzed data from 4756 breast cancer patients included in 10 randomized trials comparing neoadjuvant (NAST) and adjuvant chemotherapy. Trials were performed between 1982 and 2003. In just one trial combination of anthracyclines and taxanes was used. Primary outcomes were tumor response, the extent of local therapy, local and distant recurrence, breast cancer death, and overall mortality. Median follow up was nine years. Sixtynine percent of women allocated to NAST groups had a complete or partial clinical response and were more likely to have breast conserving treatment than patients who were operated initially ( $65 \%$ vs $49 \%)$. No significant difference between NAST and adjuvant chemotherapy was found regarding distant recurrence (15- year risk $38.2 \%$ for NAST vs $38 \%$ for adjuvant chemotherapy), breast cancer mortality $(34.4 \%$ vs $33.7 \%)$ or death from any cause $(49.9 \%$ vs $41.2 \%)$. However, NAST was associated with more frequent local recurrence than was adjuvant chemotherapy; 15year local recurrence was $21.4 \%$ for NAST and $15.9 \%$ for adjuvant chemotherapy. The local recurrence data includes both the trials with surgery and the trials in which operation could be omitted depending on the response to NAST (7).

The question is, would these higher rates of local recurrence in patients receiving NAST eventually have an impact on distant recurrence and death of breast cancer (in case of longer follow up). Perhaps we should be more prone to radiation therapy in patients receiving NAST bearing in mind worse local control it offers according to available data.

\section{Predictors of locoregional recurrence}

Following the trend towards least invasive treatment, it is necessary to define the group of patients with low risk of locoregional recurrence (LRR) in whom radiotherapy could be safely omitted.

In the combined analysis of NSABP B 18 and 27 authors defined predictors of (LRR) in patients 
given NAST. The analysis included 3088 patients with operable palpable breast cancer cT1-3N0$1 \mathrm{M} 0$, diagnosed by FNA or core needle biopsy. The axillary staging was performed with palpation only. Patients in NSABP B18 received 4 cycles of AC (doxorubicin + cyclophosphamide) pre or postoperatively and patients older than 50 were also given tamoxifen for 5 years, starting after chemotherapy. In NSABP B 27 patients received 4 cycles of neoadjuvant AC, either alone or followed by 4 cycles of neoadjuvant docetaxel or 4 cycles of docetaxel postoperatively. All patients received tamoxifen for 5 years, starting on the first day of chemotherapy, regardless of their hormone receptor status. In both studies, patients undergoing lumpectomy received breast radiotherapy alone. In case they had a mastectomy, no radiotherapy was given, which was in concordance with guidelines valid at that time. This omission of radiotherapy provides us with the natural course of the disease after NAST in context of local recurrence and helps to identify its independent predictors.

After 10 year-follow up the cumulative incidence of LRR for mastectomy patients was $12.3 \%$ (8.9\% local; $3.4 \%$ regional). Independent predictors were clinical tumor size $(>5 \mathrm{~cm})$, clinical nodal status, and pathologic nodal status/breast tumor response. Regional nodal recurrence rates were low in clinically node-negative patients, irrespective of tumour size $(2.3 \%$ to $4.3 \%$ for $\mathrm{cT}<5$ $\mathrm{cm}$ and $2.3 \%$ to $6.2 \%$ for $\mathrm{cT}>5 \mathrm{~cm}$ ). In clinical node-positive $(\mathrm{cN}+)$ patients that remained positive after NAST (ypN+), nodal recurrence rates were $4.8 \%-6.4 \%$. In 32 patients with clinically positive lymph nodes that became pathologically negative, not a single case of LRR was noticed.

Cumulative incidence of LRR for patients treated with lumpectomy plus radiotherapy was $10.3 \%$ (8.1\% local, $2.2 \%$ regional). Independent predictors of LRR in lumpectomy group were age $<50$ years, clinical nodal status and pathologic nodal status/breast tumor response. Regional nodal recurrence rates were low for patients with clinically negative lymph nodes $(0.5 \%$ to $2.3 \%)$ and for those with $\mathrm{cN}+\mathrm{ypN}-(0 \%$ to $2.4 \%)$. In $\mathrm{cN}+$ patients who remained positive after NAST rates of regional recurrence were higher: $7.5 \%$ to $8.7 \%$. Rates of LRR were generally higher for patients with at least four positive nodes compared to those with one to three positive nodes.

These results demonstrate that pathologic response in the breast and pathologic axillary nodal status has a significant impact on LRR. They also suggest that the impact of age, clinical tumor size and clinical nodal status on LRR are low in case patients achieve a pathologic complete response (pCR) and in a case the breast tumor with pathologically negative axillary nodes. Therefore, subgroups of patients with low risk of LRR that might be spared of radiotherapy and its side effects are derived (8).

However, a pooled analysis on 3481 patients from the Gepar-trials (Trio, Quattro and Quinto) gives somewhat different results. It includes patients with operable and non-operable breast cancer for which information on the use of radiotherapy (RT) was available. In these trials not only chemotherapy, but also targeted therapies were tested in neoadjuvant setting (trastuzumab in GeparQuattro, trastuzumab, lapatinib, bevacizumab and everolimus in GeparQuinto). Locoregional recurrence was defined as a recurrence in the breast, at the chest wall or in the regional lymph nodes. After a median follow-up of 55.9 months, the overall risk of LRR was $8.3 \%$. Patients who underwent radiotherapy had a significant benefit in terms of 5-year LRR-free survival (LRFS, 90\% vs. $81.5 \%$ without radiotherapy, $\mathrm{p}<0.001)$ and 5-year disease-free survival (DFS, $75.4 \%$ vs. $67.4 \%$, p < 0.001). In patients with pathologic complete response, the 5 -year LRFS was $95.7 \% \%$ with radiotherapy vs. $86.6 \%$ without radiotherapy (HR 3.32; $\mathrm{p}=0.051)$ and 5-year DFS was $86.9 \%$ and $56.1 \%$ respectively (HR 3.52; $\mathrm{p}<0.001$ ). The absolute advantage of radiotherapy regarding both LRFS and DFS was highest among patients with clinically positive lymph nodes.

Multivariate analysis confirmed radiotherapy as an independent prognostic factor for LRFS (HR 0.54; $\mathrm{p}=0.004)$ and DFS (HR 0.69; $\mathrm{p}=0.016$ ). In conclusion, patients who were not irradiated after neoadjuvant systemic treatment for breast cancer had a significantly worse outcome, even if they achieved a pCR $(9,10)$. Contrary to NSABP B18 and 27 results, according to these data, the pathological complete response should not be the reason for the omission of radiotherapy.

\section{Current clinical trial}

NSABP B-51/RTOG 1304 (NRG 9353) trial is expected to clarify whether cT1-3N1M0 breast cancer patients with the complete pathologic response in lymph nodes after NAST should receive 
regional nodal radiotherapy. Metastases in lymph nodes should be confirmed by FNA or core-needle biopsy. ER/PR and HER-2neu status before NAST is required. After NAST (with antiHER2 therapy for HER2 positive patients) definitive surgery with histological documentation of negative axillary nodes, either by axillary dissection or sentinel lymph node biopsy (SLNB) +/- axillary resection will take place. The minimal number of examined sentinel lymph nodes is three. Patients will be stratified based on the type of surgery (mastectomy vs. lumpectomy), ER status, HER2 status and pCR in the breast (yes vs. no). Upon randomization, patients in one group will not receive regional nodal radiotherapy; in case of the breast conserving surgery only breast radiotherapy will be performed, and in case of mastectomy, the patient will not be irradiated at all. In another group, patients will receive regional nodal radiotherapy, with breast or chest wall (depending on the type of surgery) included in the target volume. Regional nodes that are to be irradiated involve undissected axilla, internal mammary nodes in the first three intercostal spaces and ipsilateral supraclavicular fossa. The outcome is breast cancer recurrence-free interval rate, including local, regional and distant recurrences and deaths resulting from breast cancer. Secondary aims are also second primary cancer or DCIS occurrence, and comparison of radiotherapy effect on cosmetics in reconstructed mastectomy patients. Correlative science examines radiotherapy effect by tumor subtype, molecular outcome predictors for residual disease patients, and predictors for the degree of reduction in locoregional recurrence.

Besides being the first randomized radiotherapy trial in this indication, this trial is also important for taking into consideration tumor biology $(10,11)$.

\section{CLINICAL PRACTICE}

In clinical practice disagreements in both indications for radiotherapy and target volume definitions are being observed. Current guidelines, their occasional understatement regardless, are not always followed.

ACOSOGZ1071 prospective trial included 685 breast cancer patients staged T0-4, N1-2 M0 that underwent neoadjuvant chemotherapy. Lymph node metastases were confirmed with
FNA or core biopsy. The study was designed to evaluate the false-negative rate of sentinel lymph node biopsy (SLNB) after neoadjuvant chemotherapy. Therefore, upon chemotherapy completion, mastectomy, with or without immediate reconstruction, or breast-conserving surgery (BCS) was performed. All patients had SLNB followed by axillary dissection. Radiation therapy decisions were at the discretion of the physicians.

Of the 685 patients, 401 (58.5\%) remained node-positive following chemotherapy. In this group of patients, mastectomy was performed in $148(36.9 \%)$, mastectomy with immediate reconstruction in $107(26.7 \%)$, and breast-conserving surgery in $146(36.4 \%)$. Of the 284 node-negative patients, mastectomy was performed in $84(29.6 \%)$, mastectomy with immediate reconstruction in 69 (24.3\%) and BCS in 131 (46.1\%).

Radiotherapy was more frequently used in patients undergoing mastectomy without reconstruction; $87.9 \%$, vs. $76.1 \%$ in patients undergoing mastectomy with reconstruction $(\mathrm{p}=0.002)$. In patients that remained node-positive after NAST, radiotherapy was used in $89.9 \%$ after mastectomy and in $82.2 \%$ of patients after mastectomy with reconstruction. This difference was not statistically significant $(p=0.077)$. Final pathologic $T$ - stage, and $\mathrm{N}$-stage did not differ between these two groups. In those patients converting to node-negative after NAST, radiotherapy was employed in $84.5 \%$ of the mastectomy patients compared to $66.7 \%$ of those that underwent mastectomy with reconstruction $(\mathrm{p}<0.001)$.

Clinical target volumes differed widely. Internal mammary radiation use ranged from $7.8 \%$ to $11.2 \%$, and rates of supraclavicular radiation ranged from $46.6 \%$ to $52.2 \%$. Neither differed between surgical approaches, pathological tumor stage, or nodal response. Supraclavicular radiation was omitted in $47.3 \%$ of patients with the residual node-positive disease after NAST. Axillary radiotherapy was used more frequently in those patients remaining node-positive after NAST ( $\mathrm{p}=$ 0.002 ), and in those with residual disease in the breast $(p=0.025)$. Axillary radiation was used less frequently in patients undergoing breast-conserving surgery. It is to be noticed that $22 \%$ of patients who converted to pathologic node-negative disease and underwent completion axillary lymph node dissection received axillary radiation (12).

The impact of pathological complete response $(\mathrm{pCR})$ on disease control has been con- 
firmed in this trial. Patients with pCR had a significantly better locoregional recurrence (LRR) free survival $(p=0.003)$, distant relapse (DR) free survival $(p=0.002)$, breast cancer-specific survival $(p=0.0007)$ and overall survival $(p=0.001)$ compared to patients with residual disease. The patient who did not receive adjuvant radiotherapy had a two-fold higher risk of LRR. That difference, although not statistically significant, was also observed in $\mathrm{pN} 0$ patients $(\mathrm{p}=0.15)$. Radiotherapy was associated with a trend toward improved local-regional control in both pathological nodepositive and pathological node-negative patients. There was no difference regarding the use of radiotherapy in terms of DR, breast cancer-specific and overall survival (13).

National Cancer Database (NCDB) Analysis explored the impact of post-mastectomy and regional nodal irradiation (RNI) after neoadjuvant chemotherapy (NAC) for clinically lymph nodepositive breast cancer patients. Patients with cT13N1M0 breast cancer treated with NAS were divided into four cohorts depending on the surgical procedure (mastectomy- Mast vs. breast-conserving surgery- BCS) and post-chemotherapy pathologic nodal status (ypN0 vs. ypN+). Therefore, among 15315 patients treated in the period between 2003 and 2011, 3040 patients were classified as Mast- ypN0, 7243 as Mast- ypN+, 2070 as BCSypN0 and 2962 as BCS- ypN+. Radiotherapy field design data included breast- only, chest wall- only, breast plus RNI and chest wall plus RNI. The primary endpoint for Mast patients was overall survival (OS) from diagnosis with post-mastectomy radiotherapy (PMRT) - with or without regional nodal irradiation (RNI) - versus no PMRT. Secondary endpoint for PMRT patients was OS by RNI. For BCS patients, the primary endpoint was OS with breast radiotherapy alone versus breast radiotherapy plus RNI. BCS patients who did not undergo radiotherapy were excluded.

On univariate analysis, post-mastectomy radiotherapy was associated with improved OS in both Mast- ypN0 and Mast- ypN+ patients ( $\mathrm{p}=$ 0.019 and $p<0.001$, respectively). PMRT remained independently associated with improved overall survival in both subgroups of patients on multivariate analysis adjusted for factors including age, comorbidity score, cT stage, in-breast complete pathologic response, axillary surgery, ypN stage, estrogen receptor status and hormone therapy. Post-mastectomy radiotherapy improved overall survival in each pathologic nodal subgroup (ypN0, ypN1, and ypN2-3, all p values <0.05). In patients undergoing breast-conserving treatment no differences in overall survival were observed when adding regional nodal irradiation to breast radiotherapy in both BCS- yPN0 and BCS- ypN+ subgroups of patients. (14).

\section{CURRENT GUIDELINES}

According to NCCN guidelines, adjuvant radiotherapy should be based on maximal disease stage from pre-chemotherapy tumor characteristics at diagnosis and post-chemotherapy pathologic results. In case the patient underwent lumpectomy, adjuvant radiation is indicated to the whole breast, with or without a boost to the tumor bed. For clinical N1, ypN0, radiation to the whole breast + infraclavicular region, supraclavicular area, internal mammary nodes and any part of the axillary bed at risk should be strongly considered. For any positive axillary nodes after chemotherapy, radiation therapy as indicated to the whole breast + infraclavicular region, supraclavicular area, internal mammary nodes and any part of the axillary bed at risk.

After the mastectomy, for clinical N1, ypN0, radiation to the chest wall + infraclavicular region, supraclavicular area, internal mammary nodes and any part of the axillary bed at risk should be strongly considered. For any positive axillary nodes after chemotherapy, radiation therapy as indicated to the chest wall + infraclavicular region, supraclavicular area, internal mammary nodes and any part of the axillary bed at risk (15).

American society of clinical oncology, American society for radiation oncology and Society of surgical oncology-focused guideline update published in 2016, suggests that patients with clinical stage I or II who have received NAST prior to mastectomy should also receive postmastectomy radiotherapy in case of axillary nodal involvement that persists after NAST (less than a complete pathological response), although there are no data from randomised trials showing the effect of such treatment on long-term breast cancer mortality rates.

In case of a complete pathological response in this subgroup of patients, as well as in patients who have clinically negative nodes and receive NAST, the panel believes that there is currently insufficient evidence to recommend whether post- 
mastectomy radiation should be administered or routinely omitted. Those patients should enter into clinical trials (5).

\section{CONCLUSION}

Patients that undergo neoadjuvant systemic treatment present a heterogeneous group. Since initial pathologic report of untreated tumor, on which we base the indication, is incomplete and randomised trial data are pending, the optimal approach for this group of patients is still debatable. According to retrospective data, indication for adjuvant radiotherapy should be based on initial clinical-stage, type of surgical procedure and response of the tumor to neoadjuvant systemic treatment. In the case of any uncertainties, patient's age, comorbidities, tumor biology, and further systemic treatment option should be taken into consideration.

\section{REFERENCES:}

1. Early Breast Cancer Trialists' Collaborative Group (EBCTCG). Effect of radiotherapy after breast-conserving surgery on 10-year recurrence and 15-year breast cancer death: meta-analysis of individual patient data for 10,801 women in 17 randomised trials. Lancet. 2011;378:1707-16.

2. Early Breast Cancer Trialists' Collaborative Group (EBCTCG). Effect of radiotherapy after mastectomy and axillary surgery on 10-year recurrence and 20year breast cancer mortality: meta-analysis of individual patient data for 8135 women in 22 randomised trials. Lancet. 2014;383:2127-35.

3. Darby SC, Ewertz M, McGale P, Bennet AM, BlomGoldman U, Bronnum D, Correa C, Cutter D, Gaglliardi G, Gigante B, Jansen M-B, Nisbet A, Peto R, Rahimi K, Taylor $C$ and Hall P. Risk of ischemic heart disease in women after radiotherapy for breast cancer. N Engl J Med. 2013;368:2087-106.

4. K. Antunac. Radiation-induced angiosarcoma of the breast. Lib Oncol. 2018;46(2-3):117-120.

5. Recht A, Comen EA, Fine RE, Fleming GF, Hardenbergh PF, Ho AJ, Hudis CA, Hwang ES, Kirshner JJ, Morrow M, Salerno KE, Sledge GW, Solin JL, Spears P, Whelan TJ, Somerfield MR et Edge SB. Postmastectomy radiotherapy: An American society of clinical oncology, American society for radiation oncology and Society of surgical oncology focused guideline update. Practical Radiation Oncology. 2016;6:e219-e234.

6. Mauri D. Pavlidis N. Ioannidis JPA. Neadjuvant vs adjuvant systemic treatment in breast cancer: a meta analysis. J Natl Cancer Inst. 2005;97:188-194.

7. Early Breast Cancer Trialists' Collaborative Group (EBCTCG). Long term outcomes for neoadjuvant ver- sus adjuvant chemotherapy in early breast cancer: meta analysis of individual patient data from ten randomised trials. Lancet Oncol. 2018;19:27-39.

8. Mamounas EP, Anderson SJ, Dignam JJ, Bear HD, Julian TB, Geyer CE, Taghian A, Wickerham L et Wolmark N. Predictors of locoregional recurrence after neoadjuvant chemotherapy: results from combined analysis of national surgical adjuvant breast and bowel project B-18 and B-27. J Clin Oncol. 2012;30(32): 3960-3966.

9. Krug D, Lederer B, Debus J, Blohmer JU, Costa SD et Eidtmann H. Relationship of omission of adjuvant radiotherapy to outcomes of locoregional control and disease-free survival in patients with or without pCR after neoadjuvant chemotherapy for breast cancer: A meta-analysis on 3481 patients from the Gepartrials. J Clin Oncol. 2015;33(suppl.15):1008. DOI: 10.1200/jco.2015.33.15_suppl.1008

10. https://clinicaltrials.gov/ Accessed on February 2019.

11. Mamounas EP, Bandos H, White JR, Julian TB, Khan AJ et Shaitelman. NRG Oncology/NSABP B-51/RTOG 1304: Phase III trial to determine if chest wall and regional nodal radiotherapy (CWRNRT) post mastectomy (Mx) or the addition of RNRT to breast RT post breast-conserving surgery (BCS) reduces invasive breast cancer recurrence free interval (IBCRFI) in patients (pts) with positive axillary (PAx) nodes who are ypN0 after neoadjuvant chemotherapy (NC). J Clin Oncol. 2017;35(suppl.15): TPS589-TPS589. DOI: 10.1200/JCO.2017.35.15_suppl.TPS589.

12. Haffty BG, McCall LM, Ballman KV, McLoughlin S, Jagsi R, Ollila DW, Hunt KK, Buchholz TA et Boughey JC. Patterns of local-regional management following neoadjuvant chemotherapy in breast cancer. Results from ACOSOGZ1071 (Alliance). Int J Radiat Oncol Biol Phys. 2016;94(3):493-502.

13. Haffty BG, Ballman KV, Hunt KK, McCall LM and Boughey JC. Import of Radiation on Local Regional Control in Women With Node-Positive Breast Cancer Treated With Neoadjuvant Chemotherapy (NAC) and Axillary Lymph Node Dissection (ALND); Results From ACOSOG Z1071 (Alliance). Int J Radiat Oncol Biol Phys. 2016;96(suppl 2):S144.

14. Rusthoven G, Rabinovitch RA, Jones BL, Koshy M, Amini A, Yeh N, Jackson MW et Fisher CM. The impact of postmastectomy and regional nodal radiation after neoadjuvant chemotherapy for clinically lymph node-positive breast cancer: a National Cancer Database (NCDB) analysis. Ann Oncol. 2016;27(5):818-827.

15. NCCN Guidelines: Breast Cancer, (Version 2. 2019, July 2, 2019) at https://www.nccn.org/professionals/physician_gls/pdf/breast.pdf. Accessed on July $5^{\text {th }} 2019$.

Corresponding author: Katarina Antunac, Division of Radiotherapy and Medical Oncology, University Hospital for Tumors, Sestre milosrdnice University Hospital Center, Ilica 197, 10000 Zagreb, Croatia. e-mail: katarina.antunac@zg.htnet.hr 